\title{
An Optimized Speed Controller for Electrical Thrusters in an Autonomous Underwater Vehicle
}

\author{
K. Vinida, Mariamma Chacko \\ Department of Ship Technology, Cochin University of Science \& Technology, Kerala, India
}

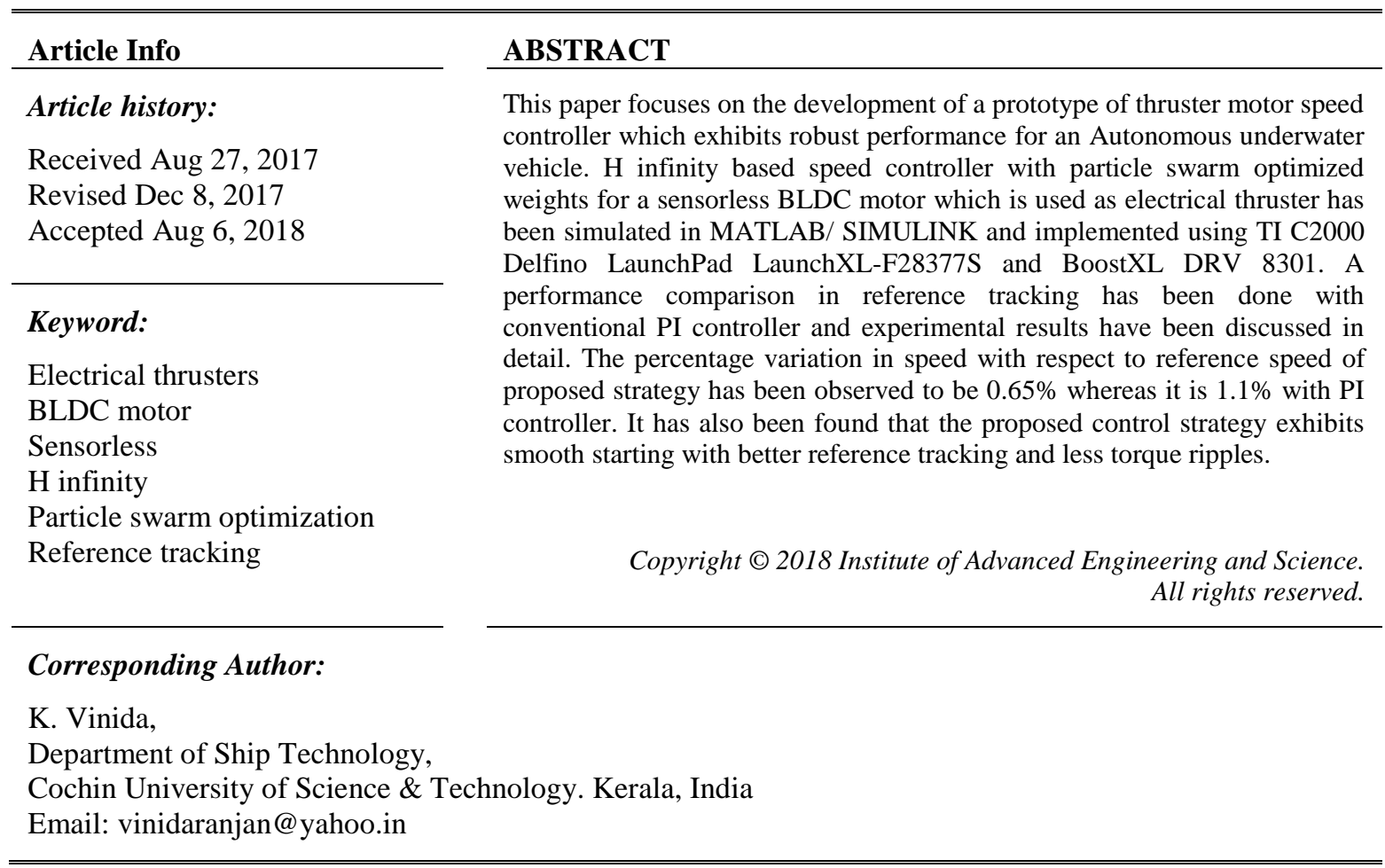

\section{INTRODUCTION}

In recent years, a lot of research work is going on in trajectory tracking control laws and path following techniques of Autonomous Underwater Vehicle (AUV) for precise maneuvering. A mission control system controls various units such as navigation, vehicle guidance and control, actuator control, data logging, communication, environmental inspection and vehicle support systems [1-2]. Of these, vehicle guidance and control block provides the reference speed to be achieved based on the reference trajectory inputs from mission control system and navigation system to the actuator control system. This is necessary for the proper trajectory tracking in the presence of uncertainties such as variation in vehicle parameters and external disturbances like varying sea currents and weather disturbances. An optimal disturbance rejection control has been derived from Riccatti and Sylvester equations for achieving optimal control in the presence of external wave disturbances. [3]. To maintain the position of AUV at a perticular depth, the scaling factors of Fuzzy logic controller have been tuned with a radial basis function metamodel and a comparative study has conducted with offline optimization approach using genetic algorithm [4].

Thruster motors with dedicated controller play an important role in the propulsion of AUV for maintaining the speed. Brushless Direct Current motors with hall sensors used as thruster motors have been found in the literature for propelling AUV [5]. The electrical and mechanical systems of a hydro quad rotor has been designed and implemented using Brushless DC motors as thrusters motors in order to study its static stability at various depths [6]. A seven phase BLDC motor for the propulsion of AUV has been functionally modelled and simulated in MATLAB/SIMULINK for studying its dynamic characteristics [7]. The analysis of electrical characteristics using Finite Element Analysis along with a comparative analysis of PI and Fuzzy controller has been done for a seven phase BLDC motor [8]. The simulation model of a BLDC motor which 
is mechanically designed as a low cost thruster in AUV has been studied for its compatibility in a depth of more than 1 meter [97]. A prototype of electrical thrusters using permanent magnet BLDC motor has been designed and implemented with 2D Finite Element Method in order to optimize the speed and torque ranges, to minimize cogging torque and to maximize efficiency [10].

Various sensorless control techniques eliminating hall sensors have been widely used in BLDC motor for rotor position detection. From the literature it has been observed that with the measurement of inductance or flux as well as by back emf detection or with estimator based models various sensorless technologies have been developed and tested [11]. Sensorless control by detecting back emf is one of the widely used methods in which the information regarding back emf can be obtained by measuring phase voltages [12] in which phase's exact commutation instants are displaced by $30^{\circ}$ from zero crossing of back emf. Calculation of difference in line voltages [13-14], second derivative of sum of three terminal voltages [15], backemf mapping [16] and backemf difference estimation [17] are some of the other techniques found in literature. The sensorless technique has been adopted by calculating the difference of terminal voltage difference which contains the information about exact commutation point which is 30 degrees lagging from zero crossing instant of back emf. The motor controller in an AUV generates an input signal to the actuator to achieve its desired velocity, based on the error signal obtained by comparing the desired values with the actual values of position and velocity obtained through sensorless techniques.

For controlling the speed of motor, various control strategies have been incorporated in the presence of uncertainties and disturbances. Proportional Integral Derivative (PID) control and PD control are used for controlling speed of BLDC motor which is used as thruster motor [18-22]. H infinity control theory has been widely used in filter design for fault detection problem [23] as well as back emf observer for sensorless control in a BLDC motor [24]. Particle swarm optimization (PSO) and Genetic Algorithm (GA) approach have been compared to find out the efficient one [25-28]. In order to attain robust control for BLDC motor exclusively in the presence of external disturbances such as ocean currents and wave drifts, $\mathrm{H}$ infinity controller with PSO optimised weights has been proposed by this author in the speed control loop and the simulation results have been discussed in detail [29-30].

For hardware implementation of speed controller, various microcontrollers have been found in the literature. PIC16F877A microcontroller has been used in the hardware implementation of speed controller of BLDC motor using PI controller [31]. A spartan-3 FPGA is used to generate the firing pulses for the MOSFETs of three phase fully controlled bridge which in turn control the speed of BLDC motor [32]. An ARM 2148 microcontroller along with HPCL 3120 MOSFET driver circuit has been used in a BLDC motor with hall sensors for position sensing and with a dynamometer as brake, to study its speed torque characteristics with the motor running in either direction [33].

This work implements a speed controller based on $\mathrm{H}$ infinity theory with weights optimized by PSO technique for a sensorless BLDC motor used in thruster for propelling AUV. The simulation results have been experimentally validated by the hardware implementation using Texas Instruments C2000 Delfino LaunchPad LaunchXL-F28377S and BoostXL DRV 8301 driver board to drive the 42BL61 BLDC motor. For saving of cost and space as well as for achieving better reliability which are the important constraints in an AUV, hall sensors have been replaced with sensorless technique for rotor position detection of BLDC motor. The significance of this work is that with the implementation of $\mathrm{H}$ infinity controller as speed controller with its weights optimized by PSO in the speed feedback loop of BLDC motor used in thrusters for propelling AUV, better reference tracking could be attained. As per present state of art, this method of implementation has not been found in the literature so far.

This paper has been organized as follows. Research method which includes the theoretical aspect of implementation of speed controller with $\mathrm{H}$ infinity theory with weights optimized by PSO technique, the hardware requirements for implementation, and various steps involved in implementation has been discussed in detail in section 2. Section 3 discusses about the important simulation and experimental results.

\section{RESEARCH METHOD}

\subsection{Hardware Realization of the controller}

The block diagram in Figure 1 represents the development of sensorless BLDC motor control. A prototype of the same has been setup as shown in Figure 2 using C2000 Delfino LaunchPad LaunchXLF28377S with Code Composer studio IDE version 6 and BoostXL DRV 8301 driver board to drive the 42BL61 BLDC motor with specifications shown in Table 1 for experimental validation. BoostXL DRV8301 has an inbuilt pre driver and six CSD18533Q5AN channel power MOSFETs. Hardware support package of C2000 F28377S has been used in SIMULINK for the development of code and the developed model has been shown in Figure 3. This code has been deployed to hardware and made to run. Phase voltages are sensed through channels 0,2 and 5 of module A and currents in each leg of inverter is sensed through 
channels 1, 3 and 4 of module A in ADC. Enhanced pwm (epwm) feature is used to generate pwm pulses with switching frequency $10 \mathrm{KHz}$. epwm and ADC have been synchronized for the proper generation of pulses.

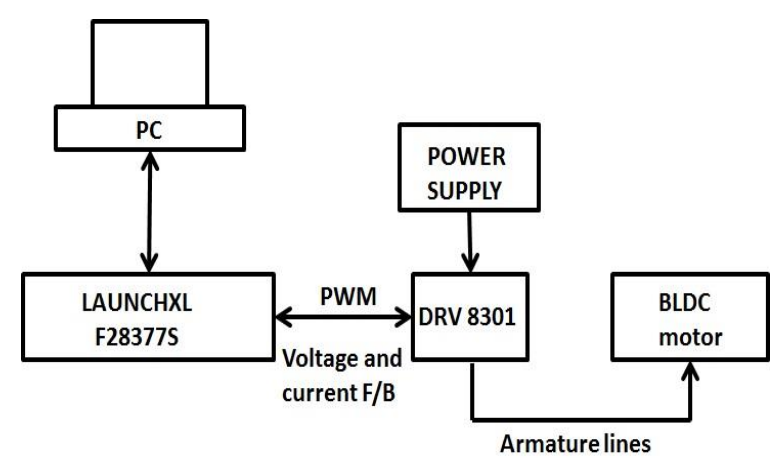

Figure 1. Block diagram depicting development of hardware setup

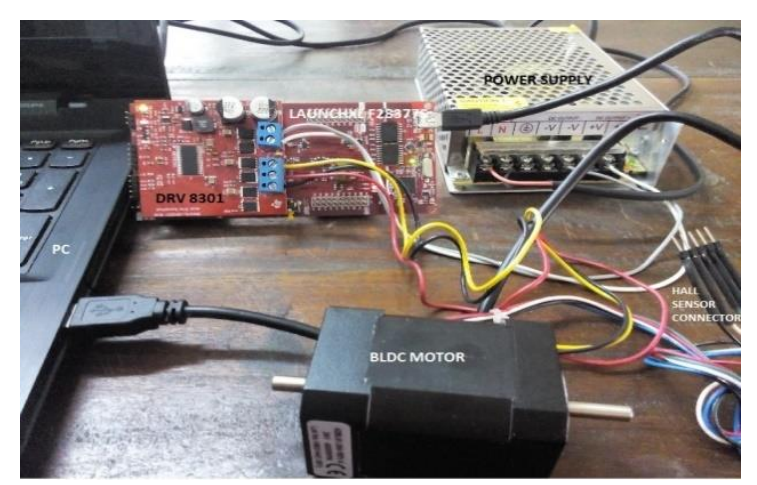

Figure 2. Experimental setup

Table 1 Specifications of BLDC motor

\begin{tabular}{cc}
\hline Parameters & Specifications \\
\hline No. of poles & 8 \\
No. of phases & 3 \\
Rated speed & $4000 \mathrm{rpm}$ \\
Rated Voltage & $24 \mathrm{~V}$ \\
Rated Torque & $0.125 \mathrm{Nm}$ \\
Torque constant & $0.036 \mathrm{Nm} / \mathrm{A}$ \\
Line to line resistance & $0.72 \Omega$ \\
Line to line inductance & $1.2 \mathrm{mH}$ \\
Peak current & $10.6 \mathrm{~A}$ \\
Moment of inertia & $0.0048 \mathrm{Kg}-\mathrm{cm}^{2}$ \\
Weight & $0.45 \mathrm{Kg}$ \\
\hline
\end{tabular}

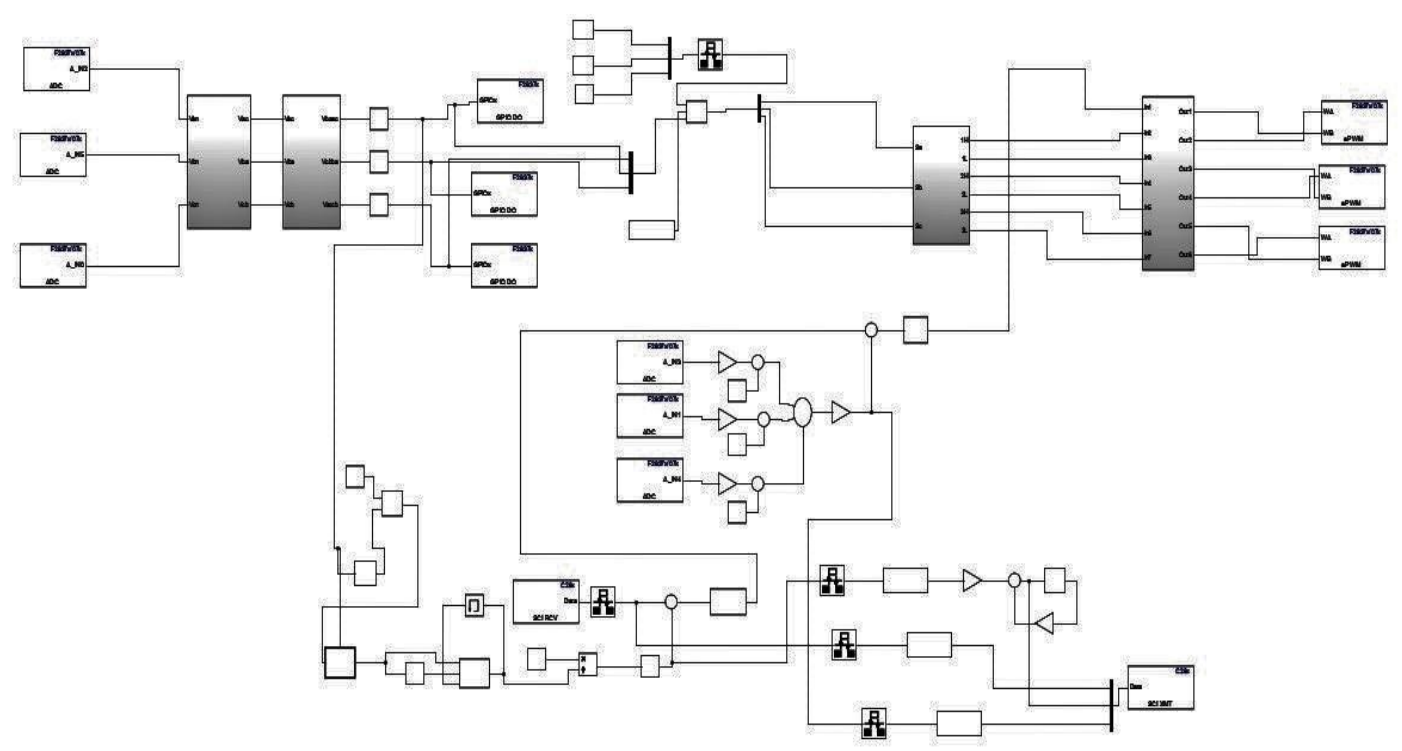

Figure 3. Developed code in SIMULINK for the system 


\subsection{Procedure for implementation}

The position and velocity of the rotor in a BLDC motor has been detected using sensorless technique by eliminating the hall sensors and a starting strategy based on the emulated hall sensor signals has been adopted.

\subsubsection{Implementation of sensorless algorithm}

In a BLDC motor, the rotor is positioned forcibly by determining the active phases and commutation of proper phase. Thus the knowledge of present position of rotor is important in the determination of correct commutation sequence. Usually hall sensors are used for detecting rotor position for proper commutation of phases. For further saving of cost and space which is an important constraint while designing an AUV, sensorless technologies pose a significant research development. The phase voltages $\mathrm{V}_{\mathrm{an}}, \mathrm{V}_{\mathrm{bn}}$ and $\mathrm{V}_{\mathrm{cn}}$ are sensed through voltage sensors of BoostXL DRV 8301 and using ADCs they are used for estimating hall sensor signals corresponding to commutating instants.

\subsubsection{Motor Starting strategy}

As the sensorless algorithm depends on zero crossing of back emf, initially motor requires a starting strategy for the back emf to build up. Once the motor rotates, back emf builds up and the rotor position can be detected, appropriate switching signals can be given for further rotation and the motor catches up with the sensorless algorithm. For achieving this, the initial hall sensor signals which are the extension of switching signals emulated by sensorless method are given for 2 seconds. Table 2 shows the emulated hall sensor signals, their corresponding commutation signals.

Table 2 Commutation signals corresponding to emulated hall sensor signals

\begin{tabular}{cccccc}
\hline \multicolumn{2}{c}{$\begin{array}{c}\text { Emulated hall sensor } \\
\text { signals }\end{array}$} & \multicolumn{3}{c}{$\begin{array}{c}\text { Corresponding commutation } \\
\text { signals }\end{array}$} \\
\hline h_a & h_b & h_c & Phase a & Phase b & Phase c \\
0 & 1 & 1 & -1 & 0 & 1 \\
0 & 1 & 0 & -1 & 1 & 0 \\
1 & 1 & 0 & 0 & 1 & -1 \\
1 & 0 & 0 & 1 & 0 & -1 \\
1 & 0 & 1 & 1 & -1 & 0 \\
0 & 0 & 1 & 0 & -1 & 1 \\
\hline
\end{tabular}

\subsubsection{H infinity based speed controller with weights optimized by PSO}

For a system to be robust, the controller should convene stability and performance requirements when the system gains and parameters are not exactly known. $\mathrm{H}$ infinity controller is a robust controller which is based on $\mathrm{H}$ infinity norm in other words maximum gain over all frequencies and in all directions as shown in Eq (1).

$$
\|\mathrm{G}\| \infty \triangleq \sup \approx[\sigma] \mathrm{G}(\mathrm{j} \omega)
$$

The block diagram illustrating the design problem is shown in Figure 4. This problem mainly concentrates on two degrees of freedom in which feedback loop corrects load disturbance and feed forward shapes reference tracking. This work mainly focuses on the reference tracking problem. Here $r$ is the reference signal, $y$ is the actual signal which is the output of process and $e$ is the corresponding error. The controller generates the control signal $u$ based on $e$ and this signal along with disturbance $d$ enters into process. The main issues in the design process are to achieve stability, to reduce the effect of load disturbances due to weather and to track reference signals obtained from vehicle guidance and control. The stability and performance requirements are met by shaping the frequency response using weighting functions which are lead lag compensators [34-35]. 


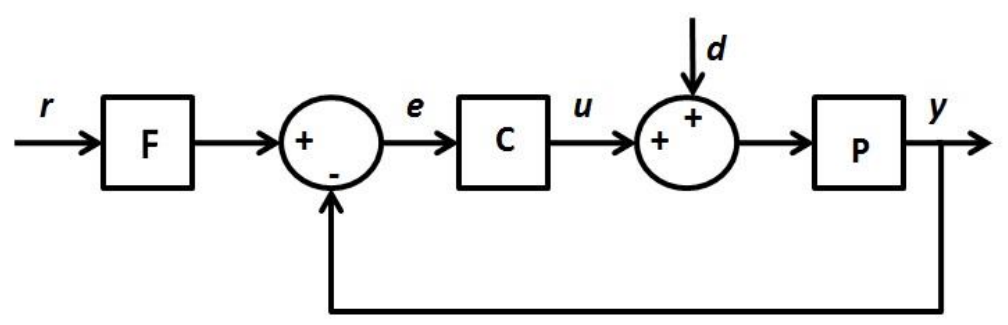

Figure 4. Block diagram depicting controller design

The weighting functions of $\mathrm{H}$ infinity controller are optimized by Particle Swarm Optimization (PSO) technique. The optimization problem is the minimization of error which is achieved by finding out the best coefficients for the weighting functions using PSO. A set of all candidate solution for the optimization problem has been defined as the search space. The population members are initialized and each particle's random position and velocity are generated. The objective function value is memorized using personal best. It is compared with the neighbor's personal best and the best value is stored in global best. The particle moves towards the new position with a new velocity along with the information regarding its current velocity, its own personal best and global best. Accordingly the optimized global best cost which is the sum of absolute values of error is obtained. With this global best cost, $W 1, W 2$ and $W 3$ are generated and transfer function of the controller is obtained. A state space model of the augmented plant $P$ has been computed for the plant $G$ along with weighting functions using the MATLAB function augw as in Eq (2) where W1, W2 and W3 denote weighting functions for error, control and output respectively.

$$
P=\operatorname{augw}(G, W 1, W 2, W 3)
$$

The block diagram shown in Figure 5 depicts the augmented plant model in which $B 1, B 2, C 1$ and $C 2$ represent disturbances, control signals, errors to be minimized and controller inputs respectively.

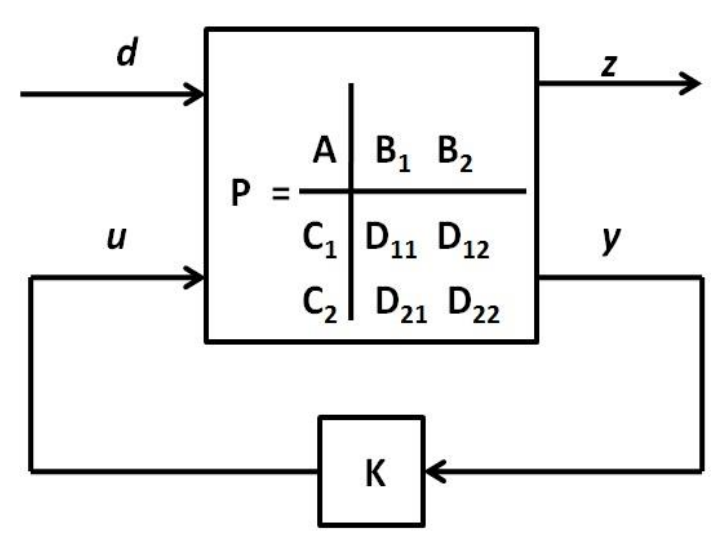

Figure 5. Augmented plant model

The MATLAB function hinfsyn() synthesizes a $\mathrm{H}$ infinity controller $K$ for the augmented plant matrix $P$ as in $\mathrm{Eq}(3)$ and the corresponding transfer function $K T$ is obtained from $\mathrm{Eq}$ (4)

$$
\begin{aligned}
& K=\operatorname{hinfsyn}(P) \\
& K T=\operatorname{tf}(K)
\end{aligned}
$$

\subsubsection{Speed measurement algorithm}

Usually the ecap feature in TI C2000 is used to capture the hall sensor signal to estimate the time period, frequency and hence the speed of rotor. This prototype has been developed using hardware support package for C2000 TMS320F28377S in MATLAB 2016a version. This version does not contain ecap feature 
in its library. Since the hall sensors are replaced with sensorless technique, here the ecap feature has been mimicked using a counter at every rising edge of one of the emulated hall sensor signal.

\subsubsection{Current control for PWM generation}

Since the rotor follows the magnetic flux vector, the speed at which this vector rotates is determined by the strength of magnetic field which is in turn controlled by applied voltage. The control of applied voltage can be achieved by switching on and off of inverter switches through high frequency PWM pulses. There is an inner current loop in order to achieve desired current proportional to desired torque whose reference is obtained from the outer speed controller. Hysteresis current control for maintaining the torque within limits has been proposed in a switched reluctance motor [36]. The actual current measurement plays a significant strategy in the generation of PWM pulses. The common strategies employed in order to measure actual current are phase current measurement in the low side of inverter legs [37] which has been adapted in this work and by generating maximum current from phase current [38].

\section{RESULTS AND ANALYSIS}

It can be observed from Figure 6 that the zero crossing instant of terminal voltage difference is the exact commutation points which can be achieved without phase compensation circuits. Thus the physical hall sensor signals are emulated by adapting this technique.

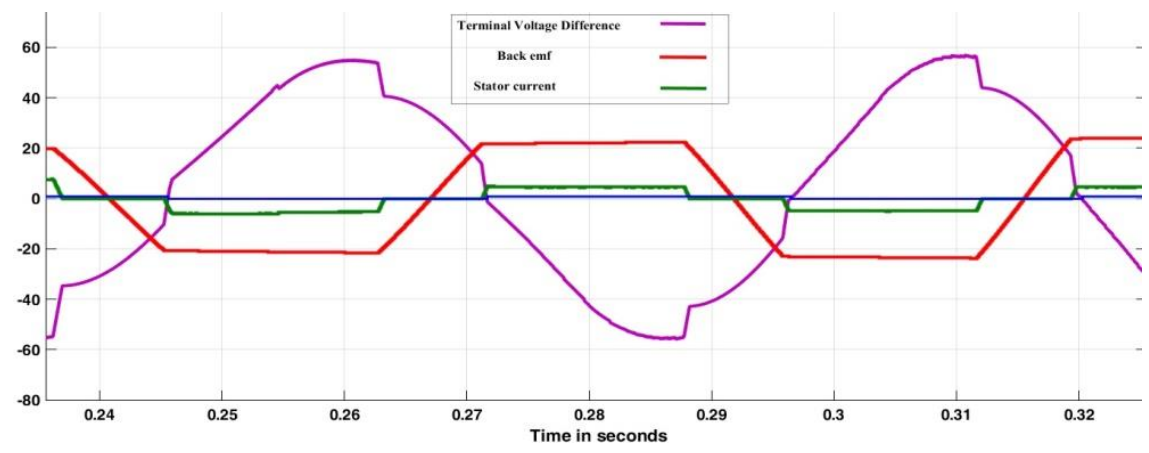

Figure 6. Simulation result obtained from sensorless technique

For verificaton purpose, the experimental result has been obtained using logic analyser as shown in Figure 7, in which the first three channels from $0-2$ depicts the physical hall sensor signal and last three channels from $3-5$ shows emulated hall sensor signal. It can be observed that the sequence is same in both methods.

Q Salese Logic 1.1.1.15-[Connected] - [12 MHz, $1 \mathrm{M}$ Samples

1 Samples $-12 \mathrm{MHz}=$ Start

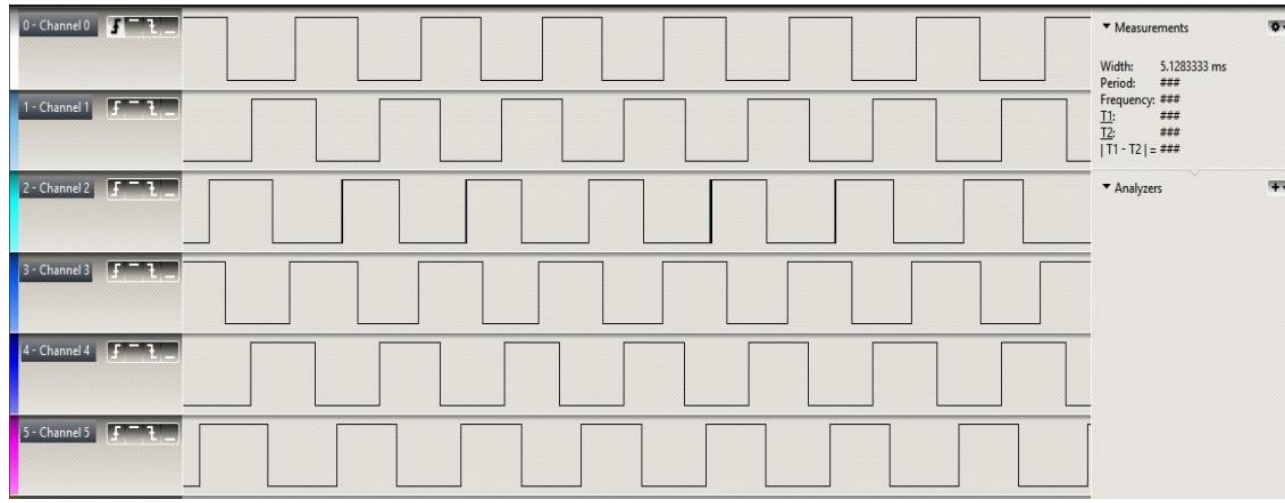

Figure 7. Screen shot of Physical hall sensor signals and Emulated hall sensor signals 
The simulation circuit of speed measurement algorithm is shown in Figure 8. For discussion purpose, the emulated hall sensor signal is replaced with a pulse generator of time period 10 milliseconds. The waveforms shown in Figure 9 show that the counter is reset at every rising edge of the pulse and the sample is held at that time. From this, the time period (T) can be obtained. Frequency is given by the reciprocal of time period and with a scaling factor speed can be obtained.

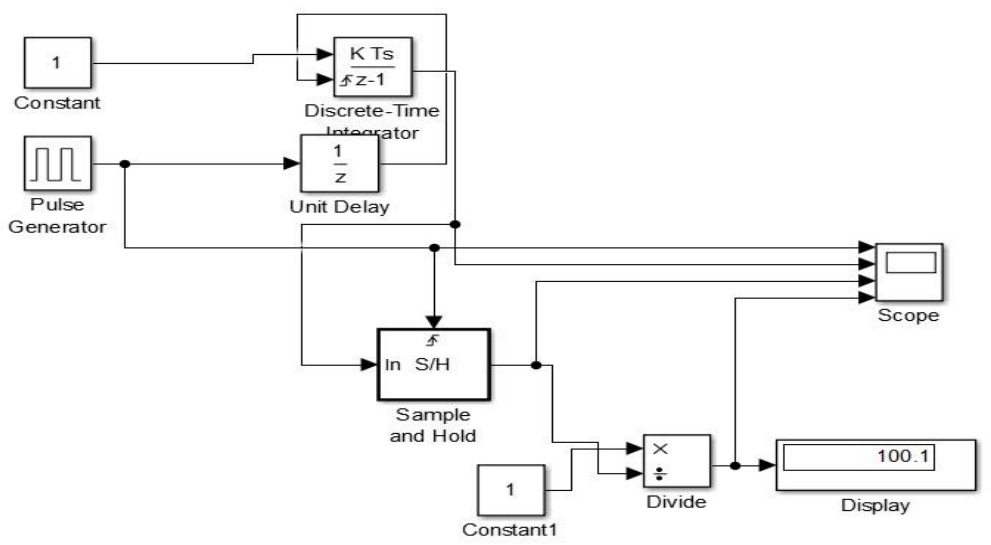

Figure 8. Speed measurement

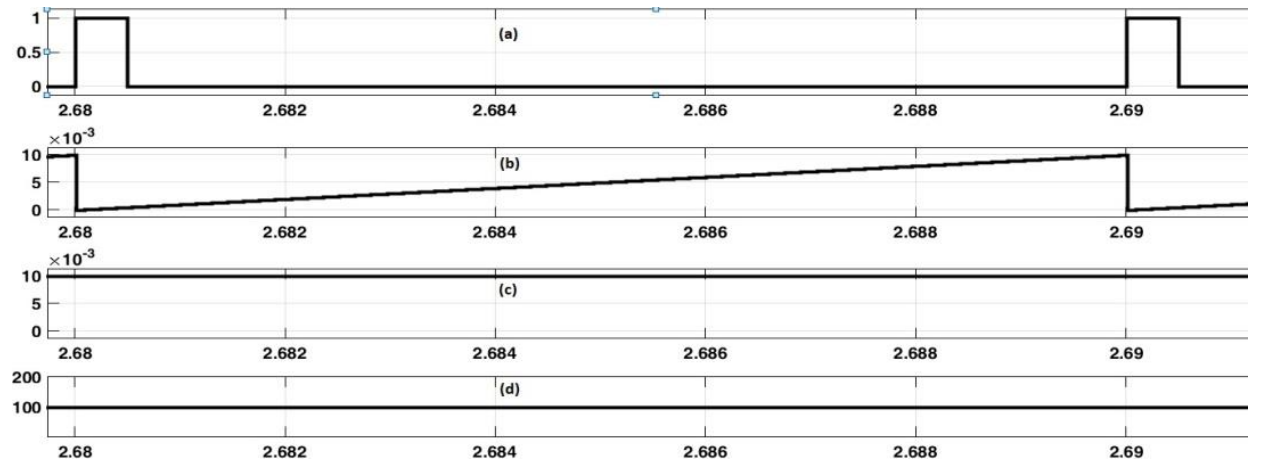

Figure 9. Simulation results of speed measurement circuit (a) Pulses (b) Counter between two rising edges (c) Time period (d) Frequency

The actual speed thus obtained is compared with the reference value and the error is passed on to the $\mathrm{H}$ infinity speed controller whose weights are optimized using PSO algorithm. The convergence plot of PSO is shown in Figure 10. The total number of evaluations is 822.

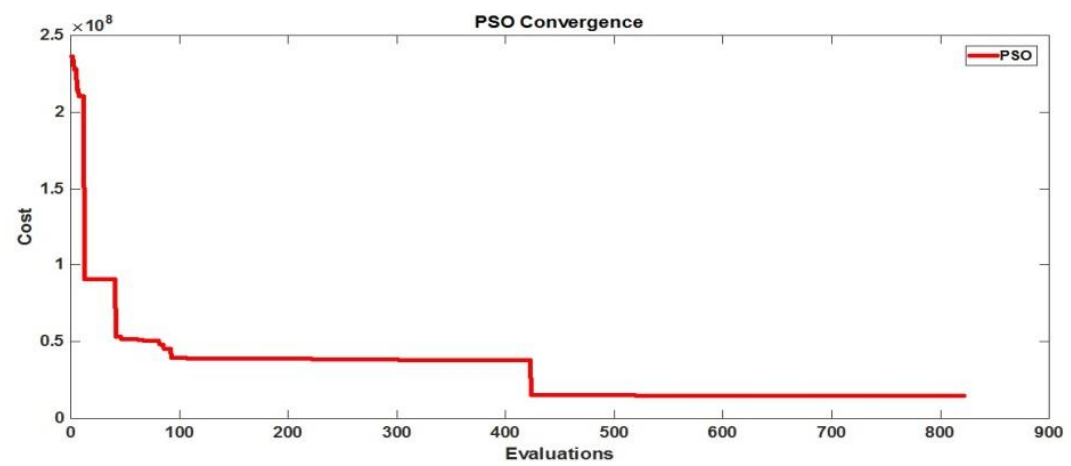


Figure 10. Convergence plot of PSO

The controller transfer function is given by Equation (5).

$K T=\frac{3206 s^{2}+4.499 e 04 s+4.45 e 08}{s^{3}+2133 s^{2}+2.097 e 06 s+1.112 e 08}$

The optimized weight $\mathrm{W}_{1}$ is given by Equation (6) and $\mathrm{W}_{2}$ and $\mathrm{W}_{3}$ are 0.16 and 0.02 respectively.

$W_{1}=\frac{0.0796 s+39.8}{0.1 s+27.36}$

The sensitivity and complementary sensitivity plots of the controller are shown in Figure 11(a) \& 11(b) respectively. It can be observed from Figure 11(a) \& 11(b) that sensitivity and complementary plots follow the trade off in which sensitivity function $S$ is low for lower frequencies thereby achieves better reference tracking as well as disturbace rejection and complementary sensitivity function $\mathrm{T}$ is lower for high frequencies which leads to insensitivity to noise and errors in modeling.

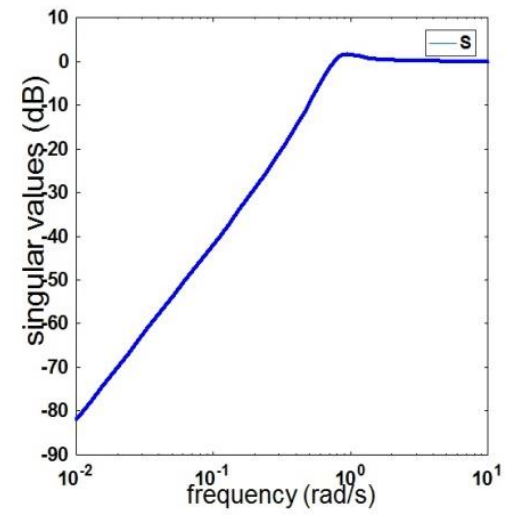

(a)

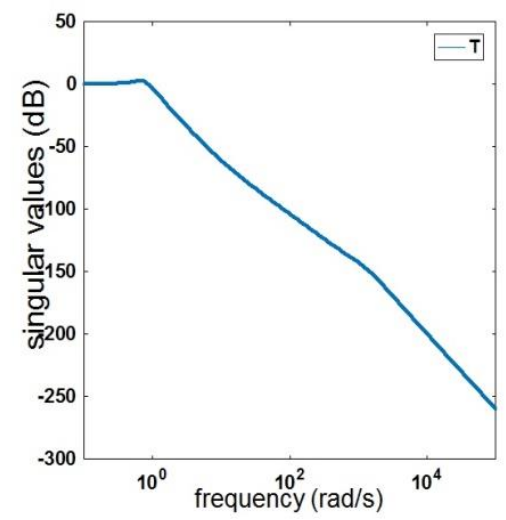

(b)

Figure 11(a). Sensitivity plot; Figure 11(b). Complementary sensitivity plot

DRV 8301 BOOSTERXL has low side current shunt sense in each leg. These current values obtained through ADCs are then added to get the average current value. Figure 12 shows the simulation result of three phase currents and their average current. This average current value is compared with the current reference value obtained from outer speed loop and the error is then passed onto the current controller which is PI controller. Table 3 shows the proportional and integral values of PI controller.

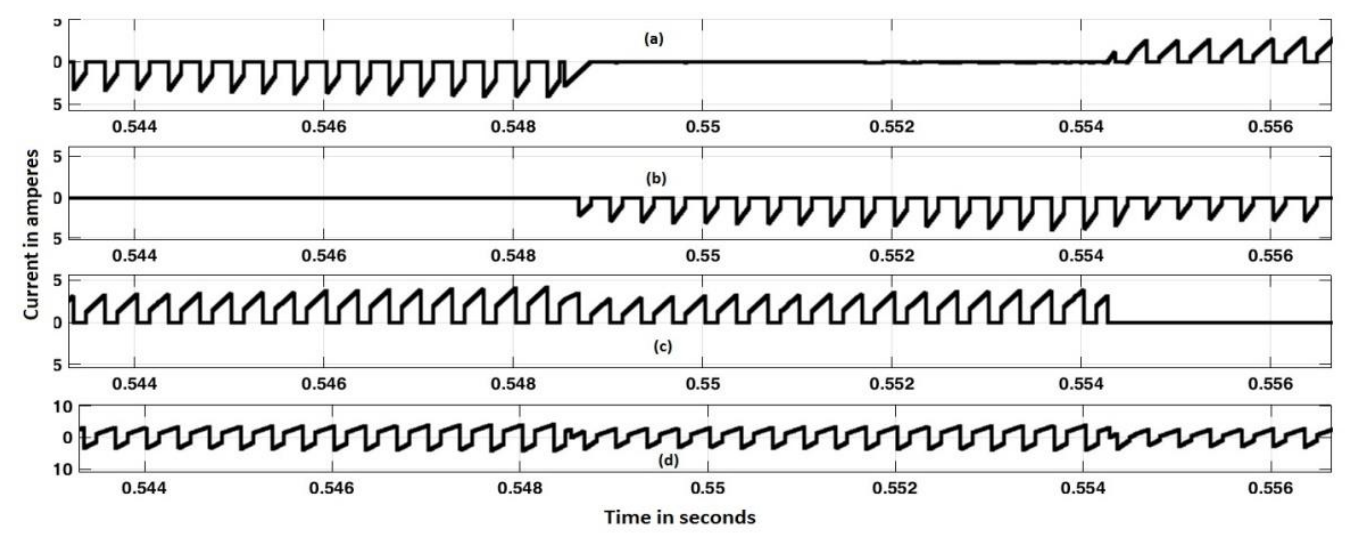

Figure 12. Simulation results showing three phase currents and the average current (a) Phase current ia (b) Phase current ib (c) Phase current ic (d) Average current 


\begin{tabular}{cc}
\multicolumn{2}{c}{ Table 3 Constants of PI controller } \\
\hline Constant & Value \\
\hline Proportional $(\mathrm{Kp})$ & 0.01 \\
Integral $\left(\mathrm{K}_{\mathrm{i}}\right)$ & 0.01 \\
\hline
\end{tabular}

The controller's output is the duty cycle and the corresponding PWM signals generated are used to switch on and off the inverter switches. The reference speed and actual speed as well as reference current and actual current values are transmitted through Serial Communication Interface (SCI) Transmit and Receive registers. The values and their corresponding waveforms are viewed and verified through Hardware In Loop (HIL) verification via SCI as shown in Figure 13.

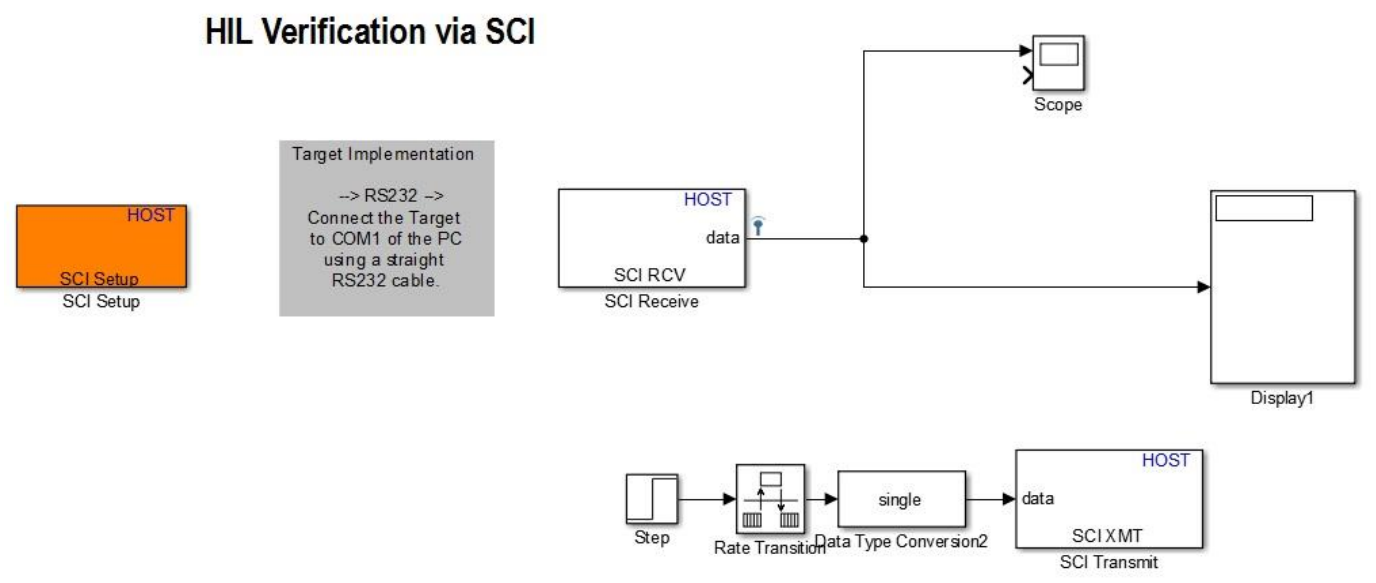

Figure 13. Hardware in Loop Verification through SCI

The reference speed has been initially set as $2500 \mathrm{rpm}$ and at 30 seconds it has been increased to $3000 \mathrm{rpm}$. The experiment has been conducted with PSO optimized H infinity controller in the speed loop whose transfer function is given by Eq (5) as well as PI controller and the results have been compared. The waveform in Figure 13 shows that both controllers track the reference speed but the PSO optimized H infinity controller with less overshoot. It has been observed that maximum percentage of variation of speed with respect to reference speed with the proposed strategy is $0.65 \%$ whereas with PI controller it is $1.1 \%$.

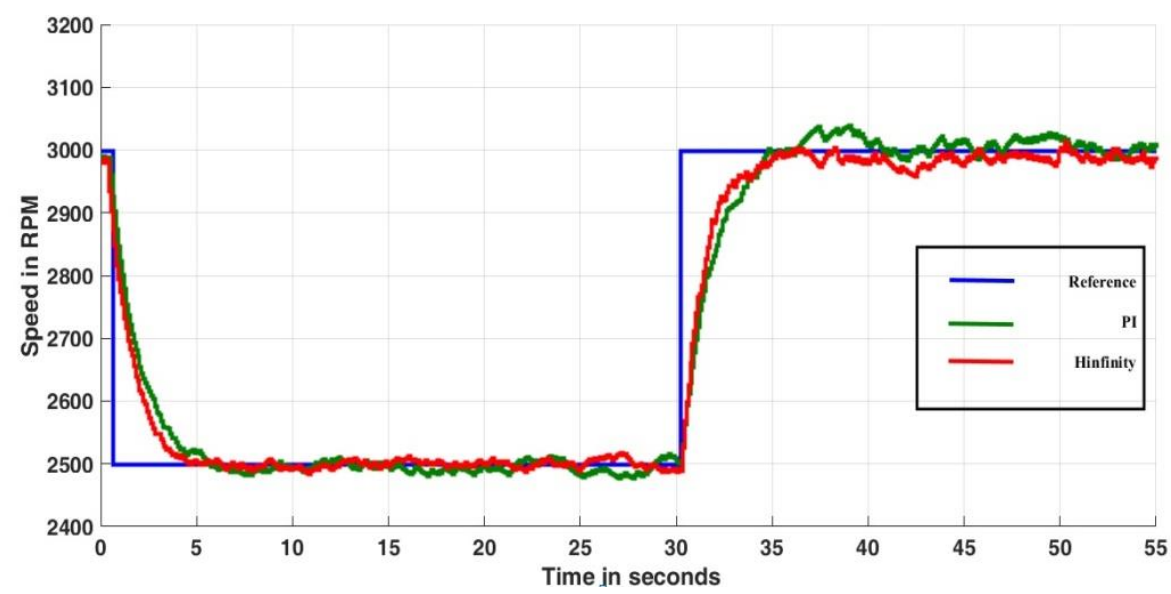

Figure 14. Reference tracking of PI and PSO optimized H infinity controllers 
Table 4 and Table 5 show the performance parameters of both PI and PSO optimised H infinity controller when the reference speed is changed from 3000rpm to initial set speed of $2500 \mathrm{rpm}$ and when it is again changed from $2500 \mathrm{rpm}$ to $3000 \mathrm{rpm}$ respectively. From Figure 15 it can be observed that the ripples in the current waveform of proposed controller strategy is less than the PI controller which implies the reduction of torque ripples.

Table 4 Comparison of parameters of both controllers when the reference speed is changed to initial set speed of $2500 \mathrm{rpm}$

\begin{tabular}{cccc}
\hline Controller & Rise time (s) & Peak Time (s) & \% Overshoot \\
\hline PI & 4.9 & 6.2 & -0.32 \\
$\begin{array}{c}\text { PSO optimized } \\
\text { Hinfinity }\end{array}$ & 4.5 & 6.5 & -0.12 \\
\hline
\end{tabular}

Table 5 Comparison of parameters of both controllers when the reference speed is changed to final set speed

\begin{tabular}{cccc}
\multicolumn{4}{c}{ of $3000 \mathrm{rpm}$} \\
\hline Controller & Rise time (s) & Peak Time (s) & \% Overshoot \\
\hline PI & 4.8 & 7.5 & 1.26 \\
$\begin{array}{c}\text { PSO optimized } \\
\text { Hinfinity }\end{array}$ & 4.6 & 6.4 & 0.1 \\
\hline
\end{tabular}

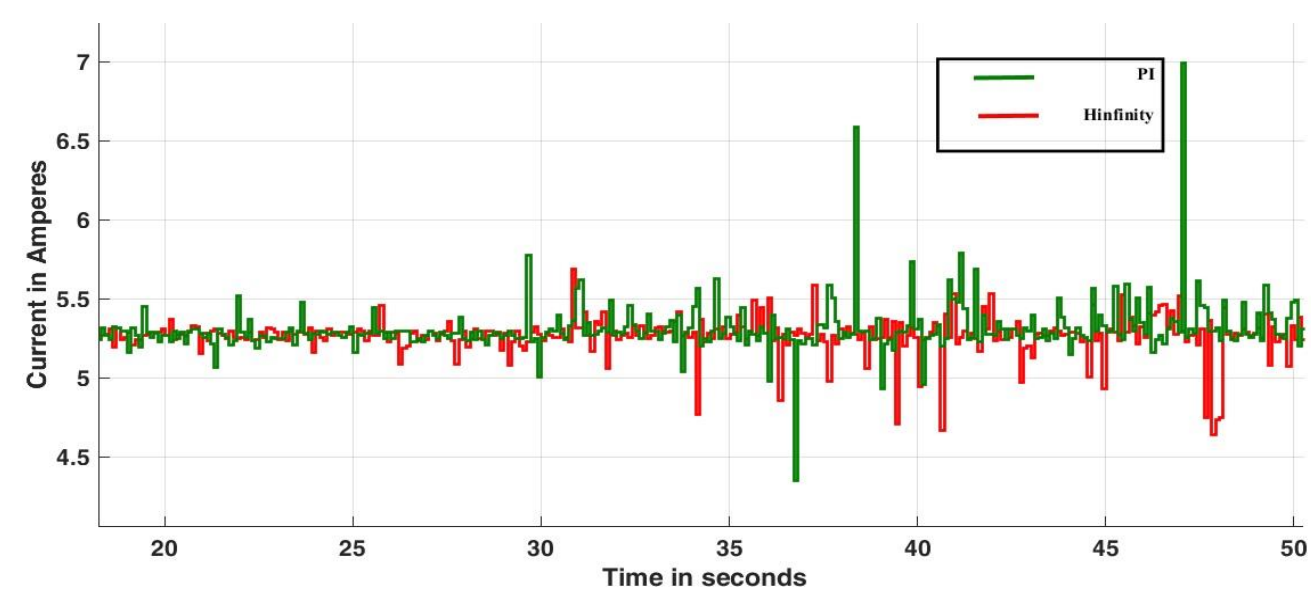

Figure 15. Current waveforms of PI and $\mathrm{H}$ infinity controllers

\section{CONCLUSION}

A prototype of $\mathrm{H}$ infinity speed controller with weights optimized by PSO technique for sensorless BLDC motor used as thruster for propelling AUV has been implemented with TI C2000 Delfino LaunchPad LaunchXL-F28377S and BoostXL DRV 8301. Corresponding hardware support package has been utilized for the development of code. The sensorless technique has been adopted by calculating terminal voltage difference and thereby hall sensor signals have been emulated. It has been observed that with reduced percentage overshoot and better reference tracking, the proposed strategy improves the overall performance of motor. Reduction in torque ripples leads to less vibrations as well as smooth transition thereby enhances the performance of an AUV.

\section{REFERENCES}

[1] Oliveira P, et al.," Mission control of the MARIUS autonomous underwater vehicle: system design, implementation and sea trials", Int J Syst Sci. 1998, 29(10),pp. 1065-80.

[2] Desa E, et al.," Potential of autonomous underwater vehicles as new generation ocean data platforms", Curr Sci. 2006, 90(9), pp. 1202-9.

[3] Qing Y, et al., "Optimal Disturbance Rejection Control of Underactuated Autonomous Underwater in Vertical Plane”, TELKOMNIKA Indonesian Journal of Electrical Engineering, 2015, 13(1), pp. 91-100.

[4] Faruq A, et al., "Optimization of an Intelligent Controller for an Unmanned Underwater Vehicle", TELKOMNIKA Indonesian Journal of Electrical Engineering, 2011,9(2), pp. 245-256. 
[5] Schultz JA, et al., “Autonomous Underwater Vehicle (AUV) Propulsion System Analysis and Optimization”, 2009.

[6] Ohol SS, et al., "Design and development of the hydro quad rotor” Int J Mech Prod Eng. (22), pp. 2320-2092.

[7] Kim T, et al., " Modeling and Simulation of Multiphase BLDC Motor Drive Systems forAutonomous Underwater Vehicles", IEEE International Electric Machines \& Drives Conference, 2007, pp.1366-71.

[8] Song S, "Autonomous Underwater Vehicles with Modeling and Analysis of 7-Phase BLDC Motor Drives", Journal of Electrical Engineering \& Technology, 2014, 9(3), pp. 932-941.

[9] Eega S, et al., "Design of a low cost Thruster for an Autonomous Underwater Vehicle Design of a low cost Thruster for an Autonomous Underwater Vehicle", 2016.

[10] Ishak D, et al., "Electrically Actuated Thrusters for Autonomous Underwater Vehicle", 11th International workshop on Advanced Motion Control, 2010, pp. 619-624.

[11] Vinida K and Chacko M, "Sensorless Control of Brushless DC motors and H $\infty$ Control Theory Applications - A Literature Review", IOSR Journal of Electrical and Electronics Engineering, 2016, 11, pp. 19-25. doi:10.9790/1676-11141925.

[12] Voultoury P, "Sensorless Speed Controlled Brushless DC Drive using the TMS320C242 DSP Controller", Application Report, 1998.

[13] Damodharan P and Vasudevan K, "Sensorless Brushless DC Motor Drive Based on the Zero-Crossing Detection of Back Electromotive Force (EMF ) From the Line Voltage Difference", IEEE Transactions On Energy Conversion, 2010, 25(3), pp. 661-668.

[14] Kim T, et al., "A New Sensorless Drive Scheme for a BLDC Motor Based on the Terminal Voltage Difference”, 37th Annual Conference of the IEEE Industrial Electronics Society, pp. 1710- 1715.

[15] Boughaba A, et al., "Robust Sensorless Control of BLDC Motor using Second Derivative Function of the Sum of Terminal Voltages", Serbian Journal Of Electrical Engineering, 2013, 10(2), pp. 275-291. doi:10.2298/SJEE130114004B.

[16] Tawadros M, et al., "Estimation of commutation instances using back emf mapping for sensorless control of brushless permanent magnet motors", IET Electrical Power Applications, 2013, 7(4), pp. 270-277. doi:10.1049/ietepa.2011.0382.

[17] Murugan M, et al, " Rotor Position Sensorless Control of BLDC Motor based on Back Emf Detection Method", TELKOMNIKA Indonesian Journal of Electrical Engineering, 2015, 14(2), pp.222-227.

[18] Cruz NA. Autonomous. Autonomous Underwater Vehicles, Intechweb.org, 2011

[19] Aziz MHRA, et al., "Model identification and control analysis for underwater thruster system", Indian Journal of Geo Marine Sciences, 2013, 42(8), pp. 992-998

[20] Buğra A. Thrust Control Design for Unmanned Marine Vehicles, Thesis, 2012.

[21] Nezvadovitz J, et al., "Design and Implementation of a Modular, High-Performance AUV”, 2015, pp. 1-10.

[22] Geetha V, et al., "Performance Analysis of Direct Torque Controlled BLDC motor using Fuzzy Logic", International Journal of Power Electronics and Drive System, 2016, 7(1), pp. 144-151.

[23] Li Z, et al., "State - space solution to the $\mathrm{H}-/ \mathrm{H} \infty$ fault-detection problem", International Journal of Robust and Nonlinear Control, 2012, pp. 282-99. doi:10.1002/rnc.

[24] Mozaffari SAKH, et al., " A new robust speed-sensorless control strategy for high-performance brushless DC motor drives with reduced torque ripple", Control Engineering Practice, 2014,24, pp. 42-54. doi:10.1016/j.conengprac.2013.11.014.

[25] Kennedy, J. and Eberhart R, “ Particle swarm optimization”, Proceeding IEEE International Conference on Neural Network, 1995, pp. 1942-1948.

[26] Hassan R, et al., “. A Comparison Of Particle Swarm Optimization And The Genetic Algorithm” 2004, pp.1-13.

[27] L. Liu, et al., "Particle swarm optimization-based parameter identification applied to permanent magnet synchronous motors, Engineering Applications of Artificial Intelligence, 2008, 21(7), pp. 1092-1100, doi: 10.1016/j.engappai.2007.10.002.

[28] M. Elkholy M and A. Elhameed M. Minimization of Starting Energy Loss of Three Phase Induction Motors Based on Particle Swarm Optimization and Neuro Fuzzy Network. Int J Power Electron Drive Syst. 2016, 7(4), pp. 103848.

[29] Vinida K and Chacko M," A novel strategy using H infinity theory with optimum weight selection for the robust control of sensorless brushless DC motor", IEEE 7th International Symposium on Sensorless Control for Electrical Drives (SLED), 2016. doi: 10.1109/SLED.2016.7518799

[30] Vinida K and Chacko M," An optimized H infinity strategy for robust control of sensorless BLDC propulsion motor in submarines for improved maneuverability", IEEE International conference on Power Electronics, Drives and Electrical Systems (PEDES) 2016. doi: 10.1109/PEDES.2016.7914280

[31] Shanmugam S K, et al., "Design and Implementation of Embedded Processor Based Brushless Motor Drive using Lead Acid Battery as Source with Lithium Ion Capacitor", TELKOMNIKA Indonesian Journal of Electrical Engineering, 2015, 14(3), pp. 455-469

[32] Suneeta, et al., "FPGA Based Control Method for Three Phase BLDC Motor", International Journal of Electrical and Computer Engineering, 2016, 6(4), pp. 1434-1440.

[33] Ramesh M.V et.al., "Speed Torque Characteristics of Brushless DC motor in Either Direction on Load using ARM controller”, IEEE PES Innovative Smart Grid Technologies - India 2011.

[34] Robert Playter, “Control system design using Hळ optimization”, Thesis, MIT, 1988.

[35] Petter Lundstrom, et al., " Weight selection of H-infinity and mu- control methods- Insights and examples from process control”, Symposium on Robust control System Design using H infinity and related methods, 1991. 
[36] Nashed MNF, Mahmoud SM, El-sherif MZ, Abdel-aliem ES. Hysteresis Current Control of Switched Reluctance Motor in Aircraft Applications. Int J Power Electron Drive Syst.. 2014, 4(3), pp. 376-92.

[37] Bridgmon J and Andrews C, "Current Sensing for Inline Motor-Control Applications", Application Report, Instruments T, 2016, pp. 1-10.

[38] Dixon JW and Leal IA," Current Control Strategy for Brushless DC Motors Based on Common DC Signal”, IEEE Transactions On Power Electronics, 2002, 17(2), pp. 232-240.

\section{BIOGRAPHIES OF AUTHORS}

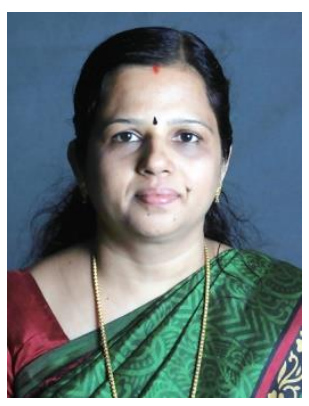

K.Vinida completed Bachelor of Engineering in National Institute of Technology, Tiruchirappalli, Tamil Nadu in 1989. She received Master of Technology from Mahatma Gandhi University, Kottayam, Kerala in 2012. She is currently pursuing her Ph.D in the department of ship Technology, Cochin University of Science and Technology, Kerala. She has published nine research papers in national, International journals and in IEEE conferences. Her areas of interest include Low Voltage energy harvesting, Drives Control, Power electronics.

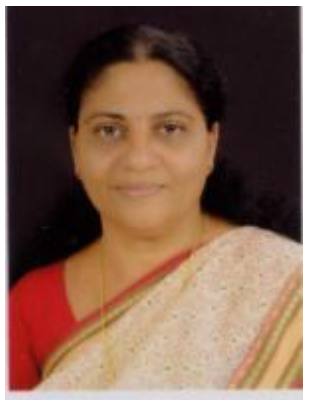

Dr. Mariamma Chacko was born in 1961 at Changanacherry, India. She received her Bachelor's degree in Electrical Engineering from University of Kerala in 1985, Master's degree in Electronics from Cochin University of Science and Technology in 1987 and $\mathrm{PhD}$ in Computer Science from Cochin University of Science and Technology in 2012. She has been working as Associate Professor in the Department of Ship Technology at Cochin University of Science and Technology since 1990, is currently the Head of the Department. From 1987 to 1990 she was associated with the Department of Electronics, Cochin University of Science and Technology, as a Research Associate. She has 15 research publications to her credit and her research interests include validation and optimization of embedded software, motor control and power quality in electrical system. 